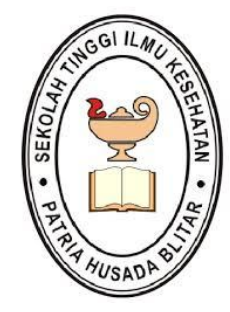

JNK

JURNAL NERS DAN KEBIDANAN

(JOURNALOFNERS ANDMIDWIFERY)

http://jnk.phb.ac.id/index.php/jnk

\title{
The Role of Health Workers in Realizing Community \\ Independence to Prevent Non-Communicable Diseases in \\ Campurejo Community Health Center, Kediri City
}

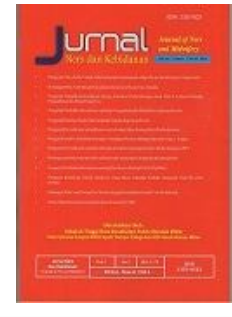

\author{
Is Fadhillah', Evita Widyawati ${ }^{2}$, Nurita Nilasari ${ }^{3}$ \\ ${ }^{1,2,3}$ Midwifery Department, Akademi Kebidanan Medika Wiyata Kediri, Indonesia
}

\begin{tabular}{ll}
\hline Article Information & Abstract \\
\hline History Article: & This study aimed to determine the understanding of health care towards \\
Received, 24/02/2021 & social phenomena related to the dominance of non-communicable diseases \\
Accepted, 30/03/2021 & which were increased in the community and to identify what efforts were \\
Published, 05/04/2021 & made by health workers in preventing non-communicable diseases. The long- \\
Keywords: & term goal of this study was to control the risk factors for PTM in Indonesia, \\
Health Workers, Community, Non- & $\begin{array}{l}\text { study used a qualitative method with } 72 \text { populations and } 10 \text { samples. The } \\
\text { data was collected through purposive sampling and in-depth interviews. }\end{array}$ \\
Communicable Diseases (PTM) & The study informants were health workers from Kediri city health office, \\
health workers at the Campurejo Health Center, community leaders and health \\
cadres. The data analysis used interactive qualitative methods (Milles and \\
Hebberman) and the instrument was recorder. The results of the study showed \\
the concept of objectivation in opposing the flow of public understanding \\
of PTM could be seen from the results of the socialization conducted by \\
health workers. This new fact could be seen from one of the efforts of health \\
workers in disseminating PTM in society. Other forms of socialization that \\
were still general in nature could be seen in a variety of activity formats, for \\
example: early detection, health promotion, counseling, mobile Posbindu, \\
and door to door systems. The five micro activities were derived from the \\
grand design of socialization in the perspective of social construction theory \\
as a form of externalization by health workers.
\end{tabular}

(C) 2021 Journal of Ners and Midwifery

\footnotetext{
Correspondence Address:

Akademi Kebidanan Medika Wiyata Kediri - East Java, Indonesia

P-ISSN : 2355-052X

Email: isfadhillah@gmail.com

E-ISSN : 2548-3811
}

DOI: 10.26699/jnk.v8i1.ART.p113-120

This is an Open Access article under the CC BY-SA license (http://creativecommons.org/licenses/by-sa/4.0/) 


\section{INTRODUCTION}

At this time health workers have a big task in their role towards the prevention of Uns transmitting Diseases (PTM). Infectious Diseases (PTM) are one of the leading causes of death in the world. Deaths from PTM in 2015 amounted to 17 million people at the age $<70$ years old. $82 \%$ of those deaths were in developing countries. The four main types of PTM causes of death are cardiovascular disease, cancer, chronic respiratory disease, and diabetes mellitus. Cardiovascular disease was the leading cause of death from PTM in 2015 at 17.7 million people. Deaths from major PTM in addition to cardiovascular disease in 2015 were cancers of 8.8 million people, chronic respiratory diseases of 3 million people, and diabetes mellitus of 1.6 million people (WHO, 2017). The majority of PTM occurs in low- and middle-income countries. Based on WHO data, PTM was the cause of $68 \%$ of deaths in the world in 2012. Predicted, PTM will continue to increase (Cahya, 2018).

PTM risk factors are related to unhealthy behaviors such as smoking, lack of physical activity, diet lack of fruit and vegetables so ptm control and prevention efforts need to change behavior. (Ministry of Health, 2012). Such an unhealthy lifestyle can lead to physiological changes in the body such as high blood pressure, high blood sugar, and high blood fats that have the potential to cause PTM. Some community interventions conducted through community empowerment in some middle-and lowincome countries show promising results in terms of sustainability or sustainability. McCloskey DJ, 2017. Health promotion strategies with community empowerment require high participation of the goal so as to have a significant impact on behavior change. This strategy has been applied to hiv primary prevention programs.

In Indonesia, several agencies have experienced implementing community empowerment in immunization programs, toddler posyandu, elderly posyandu and diarrhea control (Dewi, 2013). However, community empowerment is limited to controlling infectious diseases. Meanwhile, this study develops the role of health workers in realizing community independence for the prevention of NonCommunicable Diseases to control the risk factors for PTM in Indonesia, especially in the Campurejo Health Center area. Where this study aims to understand the social phenomena related to the dominance of non-communicable diseases that occur in the community and to identify what efforts are made by health workers in efforts to prevent Non-Communicable Diseases in the Campurejo Mojoroto Health Center, Kediri City.

\section{MATERIALS AND METHODS}

The method of the study used interactive qualitative methods which aimed to describe and understand a social phenomenon in the community regarding the understanding of health workers towards the dominance of Non-Communicable Diseases which was increasing in the community and to identify what efforts were being made to prevent Non-Communicable Diseases in the Campurejo District Health Center Mojoroto Kediri City, in improving public health status. Subjects / informants in this study were Kediri City health workers, which included health technicians involved in the prevention of Non-Communicable Diseases, Kediri City Health Office Health Workers, Campurejo Regional Health Center, Community and Campurejo Village Health Workforce Cadres where all informants met inclusion and exclusion criteria, and willingness to become informants by filling out the informed consent form. The sampling technique used in this study was purposive sampling technique. The inclusion criteria for this study informant was they are health workers from the Kediri city health office, health workers at the Campurejo Health Center, community leaders and health cadres Study location and study time in the Campurejo Community Health Center, Mojoroto District, Kediri City and the implementation time starts in July 2020.

The data was collected using a semi-structured open ended question interview type through informants who had met the requirements and reached data saturation which was then stored in a voice recorder. The data analysis technique used interactive qualitative analysis (Milles and Haberman). The analysis process was carried out during the study process. In this technique, there were three main components of analysis, namely data reduction, data presentation and drawing conclusions, all of which were focused on study objectives (Moleong, 2014).

\section{STUDY RESULT}

Health workers' understanding of social phenomena dominates non-communicable diseases which are increasing in the community. 


\section{Social Reality of Non-Communicable Diseases}

Among the social community, this NonCommunicable Disease (PTM) has become a historical fact whose existence has become an integral part in their midst. The reason is quite simple, because in general PTM has been known together and has become an everyday fact. With the usual presence of this disease, PTM seems to be a reality that does not need to be worried about its existence. So that the logical consequence, PTM seems to be ignored and considered as the flow of daily life.

Indeed, they definitively understand that PTM is a disease that is not caused by certain viruses or bacteria and will not spread to others. However, in their opinion and view PTM is solely the result of inappropriate behavior and lifestyle in daily activities (Sn: 2020, August 06). Because it is not automatically contagious, this disease only touches personally and does not relate to the people around you. So that in conclusion, they think that this disease is mediocre.

Departing from this perception, then this one disease seems to be an everyday reality and is considered a part that does not need more attention. But on the other hand, they know that these types of disease are among them. For example, hypertension, diabetes, high blood pressure, heart disease, obesity, cholesterol, stroke, and gout.

These diseases are not contagious and cannot be transmitted to others. But in fact, they are as acute as any other infectious disease and even more virulent than infectious diseases. Even in a long enough time, the disease will slowly eat away at the sufferer. Therefore, they are actually aware of the existence of PTM in their midst, but the problem is realizing it as an important part to pay attention to together such as other infectious and acute diseases.

As a result of the lack of serious attention from the community at large, the impact of this PTM finally "attacked" and infected almost all levels of society, especially those of productive age. As a result of the non-spread of these types of diseases, the community then makes them a common precaution. The point is they consider PTM as a form of disease that is not chronic, but on the other hand they are reluctant to find out as early as possible. Then the next fact, genetic or hereditary factors become one of the main causes in determining where the disease is in the eyes of society.
Generically, it cannot be denied that PTM is heavily influenced by the genetics of the family environment which is part of the "regeneration" of the disease's continuation. Even though in another history, PTM is actually also recognized as a bad impact of improper lifestyle and so on (AN: 2020, August 07).

\section{Non-Communicable Diseases and Educational Relation}

There are many factors that cause the emergence of PTM in the community, one of the most dominant is a lifestyle that is away from health values. Broadly speaking, the concept of this lifestyle actually represents all the causes of PTM itself. However, it would not be afdal if the derivation thereof was not mentioned in the following narratives. Lack of exercise is the main cause of the emergence of PTM in the social environment. As the key to building a healthy environment, exercise is very important in an effort to minimize everything related to PTM in the community (AN: 2020, August 07).

One more thing that is no less interesting for the development and growth of PTM in the community is weak and uncontrollable stress control. The existence of stress in the social environment of modern society seems to be an everyday sight. Of course all of this is not without a reason from where it comes, but stress is a negative effect of the development of the current world system network, which all seem to require us to become fast-paced and instant actors (Cn: 2020, August 03).

In the area of this exception, the level of education has absolutely an effect on the spread of PTM in the community. What is very important actually lies in the meaning of education obtained from health workers coupled with the dangers that haunt them (Cn: 2020, August 03). On this basis, then forming a community frame of mind in jointly preventing PTM in the midst of society.

\section{The Role and Response of Health Workers to Non-Communicable Diseases}

As a fact that has spread widely among the community, of course this also forms a separate frame of mind for health workers. Because after all, the educational background of health workers compared to the general public is certainly very 
different. So, it is not impossible if the understanding of health workers towards PTM is more credible and trusted than the wider community.

With this background, it is quite reasonable if the presence of health workers in responding to all this has a completely different point of view from what the surrounding community other than them think. In the view of health workers, PTM has very dangerous criteria in people's lives. Therefore, it is quite logical for health workers to respond to this disease based on their medical programs by conducting socialization, which in this case takes the form of:

\section{a. Early detection and regular health checks}

In the realm of early detection, this is mostly done formally by health workers in the community. For example, this activity is carried out with the elderly posyandu by bringing together the community at certain places and events as a medium for conducting free or paid examinations. Although on several occasions this program was not very effective because it was not uncommon for these activities to clash with community activities as workers outside their respective homes. So it is important for health workers to reschedule and consider adjustments between activities that have been designed with community activities (AN: 2020, August 07).

\section{b. Mobile Posbindu}

Not so far from the activity program above, this activity also moves in anticipating or minimizing the PTM that is so widespread in the community. It's just that what distinguishes it from the others lies in the mobilization of activities that do not stop in one place and one focus. So that thus; This activity is expected to touch all elements of society, especially within the RT and RW. This effort has become systematic because the steps taken are narrower in scope and reach the lowest level.

This Posbindu mobile activity was carried out as a more focused step to target all elements of society that so far have not been touched. Moreover, clearly this mobile activity moves from one place to another in different environments. In addition to the community, Posbindu activities are also carried out on campuses (universities) in the city of Kediri. So that the detection and results of the data obtained will be far more accurate than relying solely on formal meetings in the form of ordinary socialization.

\section{c. Extension}

The counseling referred to at this point lies in the socialization process that involves many parties in an effort to attract the wider community who are under the health control of the Campurejo Health Center. The extension process carried out by health workers in mobilizing and building independence in the prevention of PTM is to involve the role of influential community leaders in the environment where the target of this activity is carried out. Sociologically, the involvement of the role of figures has an important and influential meaning in the social environment of the community as an acceleration step in the dissemination of information to the social community related to PTM.

The second approach that is also of concern to health workers in efforts to accelerate the prevention of PTM in the social environment, namely; their involvement in arisan groups as a medium for community association. This method also becomes effective and efficient because health workers do not need to mobilize one by one the social strata of the target community. So by entering this arisan association it makes it easier for health workers to convey messages and values about how to live healthy and in accordance with health procedures.

\section{d. Health promotion}

In contrast to the concept of implementation of socialization in extension above, health promotion moves formally in a formal environment. In accordance with the target target, this health promotion is carried out by health workers in a round-the-clock way to those in certain institutions. At school, for example, health workers come to visit students to provide insight about the prevention of PTM, either due to behavior patterns in the school environment or later when they are at their respective homes.

Promotion in this school is carried out because based on the timing and opportunity, they (students) are not many in a free environment like society in general. So it is proper what these health workers do so that information and health values are really spread and known massively by all levels of society, especially those who are still in their early productive age such as the students themselves. The rationa- 
lization is easy enough why students are one of the main targets in an effort to minimize PTM in the social environment. Because the future of the nation and society rests on their shoulders, especially with regard to health problems.

\section{e. Door to door system}

In the view of the author or studyer, this last step is what best meets the standard needs of the community and health workers in minimizing PTM so that it does not drag on. The reason is, with the format and activities of the door to door system, it will be more effective in responding to all things related to this one disease. Of course, with the power to meet each community one by one in a particular environment, data collection regarding the development of fluctuations will be more controlled than in the previous program. With this step, health workers will actually have a much better understanding of the real conditions in the field related to PTM, which has been a concern of their duties.

The concept of action and practicality from several of the programs and activities above, health workers also have a pretty slick jargon in an effort to influence the style of the community so that they want to jointly build and get used to a healthy lifestyle and in accordance with common expectations, the jargon in question is CERDIK Cn: 2020, August 03): First, the initial letter of the word smart is " $\mathrm{C}$ " which is conceptualized as a periodic health check.

Second, the letter "E" which means to get rid of cigarette smoke.Third, the affiliation of the letter " $R$ " which is an acronym for diligent exercise. Fourth, in order on the letter " $D$ " which means a balanced diet. Correlated with number three above at this point, dieting can also be done through exercise. The basic essence of the diet itself actually lies in the regularity of the diet and the nutritional content of the food while still paying attention to the quality (not the quantity) of the portions of food we eat. Fifth, namely the letter "I" which is described with adequate rest.Sixth, as the last letter " $\mathrm{K}$ " which is interpreted as controlling stress.

\section{New Social Reality Post Health Promotion}

On various occasions, the observation of health workers on post-socialization developments can be found several conclusions that indicate the symmetrical condition as a result of their work during socializing with the target community. At least the minimal picture they found was in the form of enthusiasm among the people compared to the previous condition which was very difficult to describe concretely (Trista: 2020, August 04). At least this is a basic illustration of the level of public awareness in protecting themselves from noncommunicable diseases in the social environment.

It is undeniable that such facts in health promotion provide a very promising advantage in efforts to develop a healthy life in the social environment. Although in some ways, the efforts and roles carried out by health workers are not always in accordance with expectations. Evidence from all of this, for example, will later be discussed separately regarding the coverage of health figures proclaimed by health workers that are not proportional to the facts in the field. But at least with increasing public awareness in an effort to develop themselves in the realm of health, it becomes authentic evidence that the value of health and maintaining oneself to be always healthy is a separate form that needs high appreciation from health workers. For this reason, it is not easy for anyone to change the mindset of society with the blink of an eye without going through massive and systematic efforts. Moreover, all of this requires a strong commitment from all elements.

\section{Expectations and Constraints in Health Pro- motion}

In the world of numbers, it is one measure in monitoring the coverage aspect of program implementation. Likewise, in seeing the role of health workers in creating a healthy society and free from PTM. To measure these, a standard barometer is needed in the analysis of the program which is compared with the results and their relevance in the field. Thus, expectations and realities can meet within an evaluation framework of the implementation of the program itself.

The initial plan before being executed will be a reference in program implementation, and the final results of a program will be used as feedback in assessing the extent to which the program is running and how effective it is. So in this case the findings of health workers in all programs related to the 
minimization of PTM were answered only in numbers $30-50$ percent. In a sense, the initial program planned and the data in the field are still fifty-fifty. In simpler language, the program plans that are scheduled still touch 50 percent of the community in preventing PTM, because it is still around 50 percent of the initial 100 percent target, it is of course necessary to look at the obstacles and obstacles that are weak triggers for the implementation of the program itself. Thus, an internal analysis was found that one of the causes lies in the lack of health facilities to reach all levels of society. At least in this obstacle, all health check facilities are made free (for PTM) so that it can attract the opportunity of the community to be able to have themselves checked out. Lack of adequate facilities has turned out to be one of the unexpected obstacles as a form that can reduce the scope of achievements that have been previously targeted (Ls: 2020, August 07), and (Sn: 2020, August 06).

Meanwhile, another obstacle that is no less interesting is the coverage that is too broad so that it cannot be reached maximally within 100 percent. Therefore, the too broad coverage of the community is also a separate obstacle for the implementation of health promotion among the public (AN: 2020, August 07). As an important note, this coverage is also heavily influenced by the pandemic conditions that have hit almost all people in the world, including Indonesia. Thus, this unsupportive condition eventually becomes a problem in itself for health workers in an effort to socialize the program among the community. The pandemic variable also turned out to be an unexpected obstacle that greatly affected the coverage of program achievements of health workers.

\section{Campurejo Community Critical Notes}

Findings in the field from some circles reveal that the role played by health workers in efforts to minimize PTM in the community is still focused on the cadres who are under their guidance, and this has not touched much at the community level at the RT level. This note is important to use as comparative data on what has been claimed by health workers so far who claim to have done everything down to the RT and RW levels and even door to door in every community house, even though all these things have never been felt by the community (MA : 2020, August 14). However, the implicit message from the findings of the community indicates that the role of health workers needs to be maximized or re-optimized according to the scope of future expectations with a target of 100 percent PTM free society. Indeed, in one of his admissions, the role of health workers during this pandemic, many of these activities were canceled because they were simply adjusting to the conditions of Covid-19, which almost destroyed community programs. Therefore, all input and considerations both internally and externally need to be neatly accumulated as material for self-evaluation for future action development.

\section{Discussion}

In this sub-chapter of this discussion, the studyer returns to discussing in more detail most of the data presentation previously described. From presenting the existing data, the studyer then provides a theoretical perspective as a reference for reading the data that the studyer has obtained. In this discussion, the theoretical perspective used by the studyer is the social construction theory of Peter L. Berger and Thomas Luckmann. The description in this theory clearly shows that the micro or micro scope contained in the social environment of society will never be separated from the three basic concepts that exist in social construction theory, namely; externalization, internalization and objectivation (Berger, 1994). Facts in the field show that the social reality of Non-Communicable Diseases (PTM) is as common as other diseases in general. It's just that what distinguishes it from other diseases is the perception of the community in constructing PTM in their midst. Of course, it becomes clear that PTM construction among the community will receive different treatment with other types of diseases.

The reason is simple, what has become a collective agreement in the social environment of society will continue to be symmetrical with values together that it is believed to exist. Meanwhile, PTM which is deeply rooted in people's way of thinking will be difficult to change in a relatively short time. However, it does not rule out that the objectivation of a shared social existence in the community cannot go straight without continuous improvement by the next generation. Maybe now the social construction of PTM in the community is so entrenched that its existence cannot be replaced. But as a human being who always has the initiative, he must carry a counter 
value that can undermine old facts by turning them into new facts which can be completely different.

This new fact can be seen from one of the health workers' efforts to disseminate information about PTM among the community. Other forms of socialization that are still general in nature can be seen in a variety of activity formats, for example: early detection, health promotion, counseling, mobile Posbindu, and door to door systems. These five micro activities are derived from the grand design of socialization in the perspective of social construction theory as a form of externalization by health workers.

The wrong sediment regarding PTM as an ordinary disease and does not need to be minimized in the community must be countered with the new doctrine regarding PTM as a disease that must get attention and treatment by the sufferer himself. The concept of objectivation in opposing the flow of public understanding of PTM can be seen from the results of the socialization conducted by health workers. With a different statement, the results that have an impact on changing people's behavior about PTM are at least a new form of mutual objectivation among the community about the new meaning of PTM from the results of socialization.

In the analysis of social constructions, what health workers get in this context does not necessarily indicate changes in the present. But this long historical cycle requires the rays of a new chapter for generation. Although it does not rule out what people have felt today can also be practiced at this very moment. With the aim, it does not require regeneration in the future.

A further step that needs to focus on the target for the success of the role of health workers in preventing PTM is to continue to understand the new potential in the social environment as a reference for developing strategies for health workers in the future. It is highly unlikely that one strategy step will be able to answer all challenges at different times. However, it is best how different strategies are used in different situations for the purpose of finding new successes. For this reason, the next task is to continue to innovate in various systems of activities that are planned in the future. For example, is the current CERDIK jargon, is it still possible to have relevance for the socialization strategy as a way of changing people's minds for the next year, two years and three years? Of course the answer cannot be explained at this time, but the continuous evaluation of all the programs that have been implemented so far needs to get an in-depth assessment of their affective and efficacy in influencing the community.

Seeing the fact that the role of health workers in preventing PTM in the community, especially in the Campurejo Community Health Center area, can be interpreted from the initial framework of the social reality of PTM in the community continuing to the response of health workers to PTM, then the causes of PTM and then how the role of health workers regarding this one disease and reality only after the role of health workers is evidence of a symmetrical or "minimalist" fit between the program scheduled and the hope of the effectiveness of the program.

\section{CONCLUSIONS}

Based on the study data entitled The Role of Health Workers in Realizing Community Independence to Prevent Non-Communicable Diseases in the Campurejo Health Center Area, Kediri City, it can be concluded that incorrect sediment regarding PTM as a disease that is mediocre and does not need to be minimized among the community must be countered with the new doctrine regarding PTM as a disease that must get attention and treatment by the sufferer himself. The concept of objectivation in opposing the flow of public understanding of PTM can be seen from the results of the socialization conducted by health workers. With a different statement, the results that have an impact on changing people's behavior about PTM are at least a new form of mutual objectivation among the community about the new meaning of PTM from the results of socialization. This new fact can be seen from one of the health workers' efforts to disseminate information about PTM among the community. Other forms of socialization that are still general in nature can be seen in a variety of activity formats, for example: early detection, health promotion, counseling, mobile Posbindu, and door to door systems. The five micro activities are derived from the grand design of socialization in the perspective of social construction theory as a form of externalization by health workers. 


\section{SUGGESTION}

For respondents/ the community, the results of this study should be used as additional insights and knowledge of community about the importance of Realizing Community Independence to Prevent Non-Communicable Diseases.

\section{REFERENCES}

Berger, Peter L. (1994). LangitSuci; Agama Sebagai Realitas Sosial. LP3ES. Jakarta.

, Peter L\& Luckmann, Thomas. (2013). Tafsir Sosial Atas Kenyataan; Risalah Tentang Sosiologi Pengetahuan. LP3ES. Jakarta.

Cahya Adhania, Cindy dkk. (2018) Prevelensi Penyakit Tidak Menular Pada Fasilitas Kesehatan Tingkat Pertama di Kota Bandung Tahun2013-2015 .JSK Volume 3 Nomor 4 UniversitasPadjajaran Bandung.
Dewi FST, Stenlund H, Marlinawati VU, Oh-man A, Weinehall L.(2013). A Community Interven-tion for Behaviour Modification: An Experi-ence to Control Cardiovascular Diseases in Yogyakarta, Indonesia. BMC Public Health.;13(1):1043.

Kementerian Kesehatan Republik Indonesia. Data dan Informasi Kesehatan Penyakit Tidak Menular. (2012). Jakarta: Kementerian Kesehatan RI; 2012:48.

McCloskey DJ, McDonald MA, Cook J, Ro-berts SH, Updegrove S, Sampson D, et al. Eva-luation of Community-Based Interventions for Noncommunicable Diseases: Experiencesn from India and Indonesia. - PubMed - NCBI. (cite 2017Mar 29). Availablefrom:https://www.ncbi.nlm.nih.gov/ pubmed/21071458(3). Diakses 27 Maret 2019

Remais J, Zeng G, Li G, Tian L, Engelgau M. Convergence of non-communicable and infectious diseases in low- and middle-income countries. International Journal of Epidemiology. 2012;42(1):221-227.(2) 